\title{
Experimental Study on the Mechanical Properties of Biomass Briquettes from Different Agricultural Residues Combination
}

\author{
Law H.C ${ }^{1, *}$, Gan L.M ${ }^{1, \dagger}$, and Gan H.L ${ }^{1}$ \\ ${ }^{1}$ Faculty of Mechanical Engineering, Universiti Malaysia Pahang, 26600 Pekan, Pahang, Malaysia.
}

\begin{abstract}
Biomass has received tremendous attention as it is one of the best alternatives to replace the use of fossil fuels for energy generation. However, there are problems associated with the utilization of raw biomass which could be resolved through densification process. Besides, mixing between residues could produce a quality briquette, at the same time making good use on the biomass residues. Rice husk, sugarcane bagasse and spent coffee ground were selected as the biomass feedstocks for briquettes formation. The mixing ratios of 100:0, 80:20, 60:40, 20:80, 40:60 and 0:100 were used for three different combinations. The briquettes were then compacted at 300 bars and $150^{\circ} \mathrm{C}$ for $30 \mathrm{~s}$. The mechanical properties of the briquettes were measured with respects to their shatter resistance, abrasive resistance as well as water resistance. The mechanical properties of the briquettes could be effectively improved by mixing between the residues as compared to the pure materials. The result showed that briquettes formed with 40: 60 of $\mathrm{RH}$ to SB; 20: 80 of RH to SCG and 20: 80 of SB to SCG were among the optimum mixing ratio for the respective combination fulfilling the specifications of the mechanical strength and durability.
\end{abstract}

\section{Introduction}

The utilisation of fossil fuels has resulted in the anthropogenic greenhouse gas (GHG), especially $\mathrm{CO}_{2}$ emissions and thus threatening the environment as well as future human society's development [1]. As reported by Garrett-Peltier [2], the global carbon emissions have come to an unsustainable level, and therefore the global energy system must be transformed in order to limit global climate change to a $2{ }^{\circ} \mathrm{C}$ rise above pre-industrial levels by 2100 . Renewable energy therefore is one of the primary alternatives to mitigate the emissions problem.

According to Dermibas [3], biomass appears to be the world's fourth largest energy source, after coal, crude oil and natural gas due to its sustainable supply and able to mitigate the Greenhouse gases (GHG) emissions. In Malaysia, about 150 billion metric tons of agricultural biomass waste are generated annually [4], indicating the sustainability and availability of the renewable resources for energy generation.

\footnotetext{
* Corresponding author: chit0828@gmail.com

$\dagger$ Corresponding author: ganlm1980@ gmail.com
} 
Agricultural wastes have been targeted as the potential energy source worldwide, especially in the countries with intensive agricultural practices including Malaysia. Missagia and colleagues [5] mentions that the use of agricultural biomass as the renewable energy feedstocks is favoured for its use will not threaten the food security or impede the traditional agricultural practices. On top of that, additional benefits with the development of biomass energy from agro-residues are listed as follows: clean and sustainable, inexhaustible; Economic development; generate rural incomes; accelerate industrialization of agriculture and minimise environmental pollution. There are two categories of biomass conversion technologies, namely biochemical process and thermochemical process that could be applied to convert the raw biomass into value-added chemicals, fuels, heat and power [6]. To date, biomass also can be used as a solid fuel and directly burnt for heat and power generation [7].

Nevertheless, the utilization of the raw biomass often associates with the problems of moisture content, irregular in shape and size as well as low bulk density which may trigger to the problems of handling, storage, transportation and utilization as a fuel [8]. These challenges could be upgraded through the process of densification in order to expand the use of biomass in energy generation. With the application of pressure and temperature, the loose and bulky residues are compacted to form a uniform sized and shaped pellets, briquettes, cubes and etc. A quality densified fuel with adequate strength and durability was desirable as to ease the subsequent processes such as handling, storage, and feeding. However, there are a few factors need to be considered which are claimed to have influenced the quality of the densified products, for instance moisture content, compacting pressure, preheating temperature as well as mixing of biomass materials [8].

As acknowledged, mixing of biomass materials is beneficial in the enhancement of strength and durability of the densified product [8]. Muazu and Stegmann [9] mentioned that there are problems with the usage of briquettes formed from the pure materials, therefore mixing of rice husk and corn cob has been done to raise the fuel quality. In addition, the physical characteristics of the rice straw briquettes are proved to be enhanced by using sawdust as binder [10]. Another point of view, on the hand, was reported by Lund, Byrne, Bernde and Vasalos [11] whereby the biomass materials are found to be difficult to be blended with either other types of biomass and/ or coal due to their different characteristics in terms of particle size, bulk density as well as flowability.

As a result, the application of an appropriate technology or process is essential, including the determination of preheating temperature, compacting pressure as well as mixing ratio so that the biomass residues can be used effectively as the energy source. The aim of this paper therefore is to produce the briquettes with biomass residues blends and different mixing ratio without addition of binders. Then, the mechanical properties of the biomass briquettes formed were investigated which can lead to the determination of the optimized mixing ratio.

\section{Experimental procedures}

\subsection{Biomass Residues Selection}

Rice husks, sugarcane bagasse and spent coffee ground were selected as the biomass feedstocks for the briquettes formation in this study. The selection was based on their substantial quantities and sustainability in Malaysia, at the same time could be easily accessed near the research area.

These residues are having potential as the energy source and have been used for heat and electricity generation. For instance, rice husks and spent coffee ground had been used for the solid fuel production, whereas sugarcane bagasse was adopted for bio-ethanol formation. 


\subsection{Raw Material Preparation}

The collected waste biomass would normally come with high moisture content as well as in bulky, wet and loose form which could not be directly briquetted into a solid fuel. Raw materials with high moisture content might trigger to the poor grindability and also require higher energy for size reduction [12]. Therefore, the raw materials must be dried whereby their moisture content was controlled in the range of 8 to $15 \%$, as suggested by Pandey and Dhakal [13].

The subsequent process would be size reduction, which could help to increase the biomass pore size and the total surface area too for binding purpose [14]. The dried materials, except spent coffee ground which was originally in powder form, were reduced in size by using the specifically designed grinding facility. This particular facility was equipped with four pairs of shear and hammer mill screen size of $2.0 \mathrm{~mm}$. The grinding speed of the facility ranged from $500 \mathrm{rpm}$ to $580 \mathrm{rpm}$, varying with different materials and as the result the finer even powder-form particles were obtained. The dried and ground raw materials were portrayed in Figure 1.

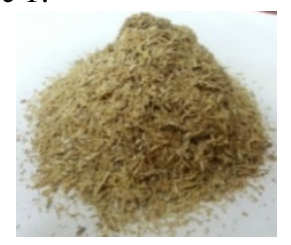

(i)

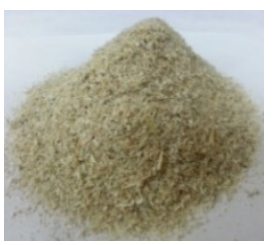

(ii)

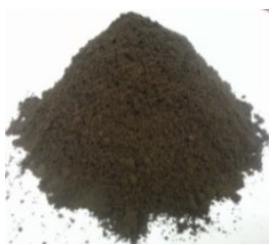

(iii)

Fig. 1. Ground raw materials of (i) rice husk; (ii) sugarcane bagasse and (iii) spent coffee ground.

All the ground materials were filled in the air-tight plastic bag in order to inhibit the surrounding moisture and impurities that could affect the quality of briquettes formed subsequently.

\subsection{Biomass Briquette Production}

\subsubsection{Mixing of biomass residue}

Mixing of biomass materials was incorporated in this study. Based on the selected biomass feedstocks, there are three different combinations could be formed: Rice husk (RH) and Sugarcane bagasse (SB); Rice husk and spent coffee ground; sugarcane bagasse and spent coffee ground (SCG). The mixing ratio of briquettes produced was presented in Table 1. Besides that, the briquettes made from pure residues would be given the denotation of mixing ratio as 100:0 and 0:100.

Table 1. Sample combination and the mixing ratio.

\begin{tabular}{|c|c|}
\hline Biomass combination & Mixing ratio (wt. \%) \\
\hline \multirow{4}{*}{ RH:SB } & $80: 20$ \\
\cline { 2 - 2 } & $60: 40$ \\
\cline { 2 - 2 } & $20: 80$ \\
\cline { 2 - 2 } & $40: 60$ \\
\hline \multirow{3}{*}{ RH:SCG } & $80: 20$ \\
\cline { 2 - 2 } & $60: 40$ \\
\cline { 2 - 2 } & $20: 80$ \\
\hline \multirow{2}{*}{ SB:SCG } & $40: 60$ \\
\cline { 2 - 2 } & $80: 20$ \\
\hline & $60: 40$ \\
\hline
\end{tabular}




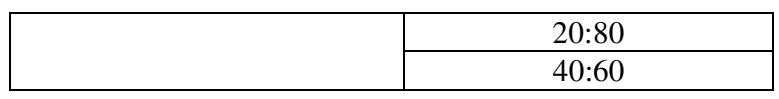

\subsubsection{Briquetting parameter determination}

With regard to biomass densification or briquetting, pressure was applied with or without heating and binders to overcome the elastic nature of the agricultural wastes and convert them to a compact agromate [15]. In accordance to the objective of this study, self-briquetting technique was applied for briquette formation, and hence preheating temperature coupled with compacting pressure were incorporated in the briquetting process with no binders added.

In accordance to the specification of the briquetting facility, the maximum pressure could be reached by the hydraulic press was 400 bars. From the preliminary testing, the compacting pressure was fixed at 300 bars in order to generate the densified products with adequate strength.

According to Adapa, Tabil and Schoenau [16], the plant lignin was the natural binder which could be softened and activated when higher temperature was applied during densifiction, and thus promoting a better binding process. On top of that, lignin owned the thermosetting properties and a low melting point of about $140{ }^{\circ} \mathrm{C}$. On the contrary, too high of temperature might dry up the biomass, subsequently causing blockage and of the materials inside the die as well as reducing the durability of the sample product [17]. Therefore, the preheating temperature applied in the experimental was set to be $150{ }^{\circ} \mathrm{C}$.

In the case of holding time, Ndindeng et al. [18] emphasized that the briquettes produced with the holding time from 20 to $40 \mathrm{~s}$ were having least percentage relaxation. In addition, Wongsiriamnuay and Tippayawong [17] stated that 10 to $60 \mathrm{~s}$ of holding time could prevent the spring back effect after compaction. With the foregoing statements, the dwell time was fixed to be $30 \mathrm{~s}$.

\subsubsection{Briquetting process}

Approximately $10 \mathrm{~g}$ of ground materials (according to the mixing ratio listed in Table 1) were weighed by using a pocket scale with the accuracy up to $0.01 \mathrm{~g}$ and mixed well. A hydraulic press with the specifically designed piston and mold was adopted throughout the briquetting process. The doughnut-shaped briquette with the outer diameter of $50 \mathrm{~mm}$ was the endproduct produced according to the pre-determined briquetting parameters as shown in Figure 2.

Fig. 2. Example of briquette formed.

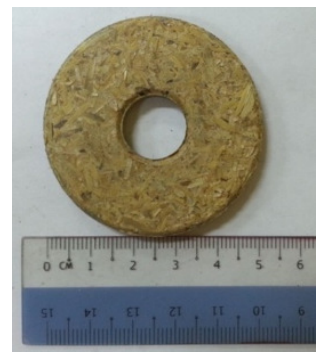

The briquettes extracted from the mold were normally hot and plastic, thus they were placed aside for cooling before being stored in the containers with labels. The densified products were then kept at room temperature in order to restrain the surrounding air moisture which might affect the subsequent analysis result. 


\subsection{Measurement on mechanical strength and durability}

The mechanical properties of the densified products were one of the important factors for the consumers to measure the quality of the briquettes. As reviewed by Kaliyan and Valence Morey [8], three relevant tests namely shatter resistance, abrasive resistance and water resistance test scould be conducted to measure the effectiveness of the inter-particle bonds of the briquettes.

\subsubsection{Shatter resistance}

The shatter resistance might help in simulating the forces encountered when emptying the briquettes from trucks onto ground, or shifting from one place to another [8]. On top of that, the safe height of briquette production also could be determined through this particular experiment testing.

The method adopted in the research done by Sengar et al. [19] and Birwatkar et al. [20] was selected in this study. The sample was dropped onto the concrete floor from $1 \mathrm{~m}$ high for 10 times continuously. Table top with an adjustable platform together made up the designated height of $1 \mathrm{~m}$, as illustrated in Figure 3.

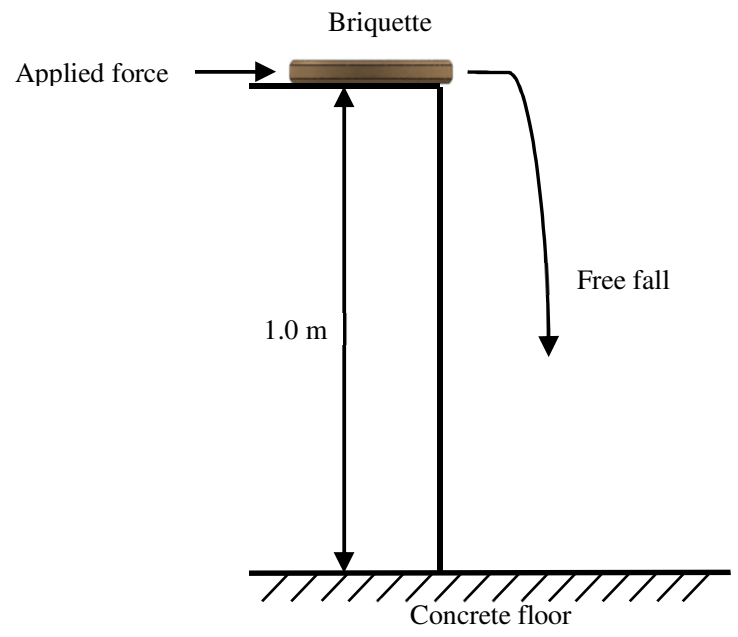

Fig. 3. Schematic diagram for drop test.

Shatter resistance of the briquettes was calculated by using the following equations, whereby the weight of the sample briquettes was recorded before and after shattering, and thus the percentage of shatter resistance could be calculated

$$
\begin{aligned}
& \text { weight loss }(\%)=\frac{W 1-W 2}{W 1} \times 100 \% \\
& \text { Shatter resis } \tan c e(\%)=100 \%-\text { weight loss }(\%)
\end{aligned}
$$

where $W_{1}$ is initial weight $(\mathrm{g})$ whereas $W_{2}$ represents final weight $(\mathrm{g})$. 


\subsubsection{Abrasive resistance}

The abrasive resistance test, also known as tumbling test was the measure of the mechanical durability of densified products in consequence of transport and handling processes. The briquette was subjected to controlled shocks by collision of fuel particles against each other's and against the walls of a rotating chamber.

The tumbling process was conducted with the speed rate of $25 \mathrm{rpm}$ for 5 minutes in clockwise direction by referring to the standard of EN 15210-2 (2010) [21]. Sieving was required before and after tumbling for $30 \mathrm{~s}$ to remove the fines attached to the sample. The illustration of the tumbling test was displayed in Figure 4.

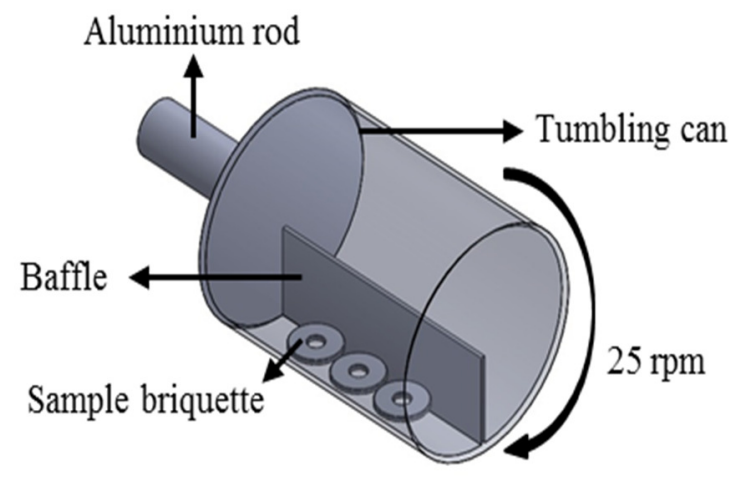

Fig. 4. Schematic diagram for tumbling test.

The equations used to determine the abrasive resistance of the densified products were portrayed as follows:

$$
\begin{aligned}
& \text { weight gained }(\%)=\frac{W a-W b}{W a} \times 100 \% \\
& \text { Abrasive resis tan ce }(\%)=100 \%-\text { weight loss }(\%)
\end{aligned}
$$

where $W_{\mathrm{a}}$ is weight of briquette before tumbling $(\mathrm{g})$, whereas $W_{\mathrm{b}}$ is weight of briquette after tumbling $(\mathrm{g})$.

\subsubsection{Water resistance}

Other than implying destructive forces to the briquettes for strength determination, water permeability is also one of the crucial aspects to be considered especially when dealing with storage, transportation and handling. The structure could not sustain in shape and crumble easily due to the weak inter-bonding, and thus creating problem to the combustion.

Water resistance of the solid fuels was measured through the immersion test. A $200 \mathrm{ml}$ beaker was filled with $100 \mathrm{ml}$ of water at room temperature as portrayed in Figure 5. The initial weight of each briquette was recorded before the immersion. At the same time, a stopwatch was used to record the immersion duration at $30 \mathrm{~s}$. This immersion procedure was performed according to the research done by Davies and Davies [22]. 


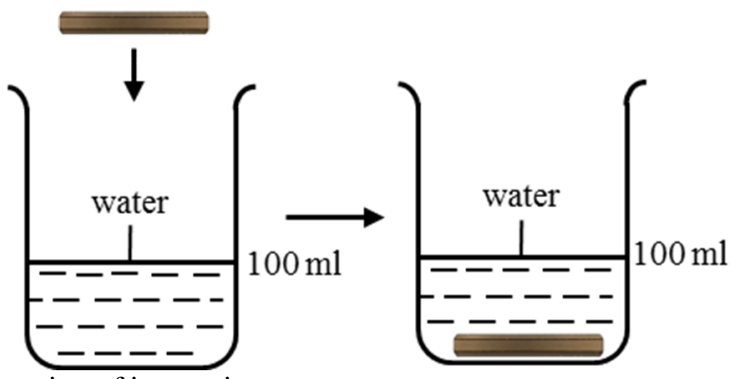

Fig. 5. Schematic illustration of immersion test.

After the immersion, the briquette was extracted from the beaker and the final weight was obtained. The percentage of water gained by each briquette was calculated by using the equations as followed:

$$
\text { weight gained }(\%)=\frac{W \mathrm{ii}-W i}{W i} \times 100 \%
$$

Water resis $\tan c e(\%)=100 \%-$ weight gained $(\%)$

where $W_{\mathrm{i}}$ is weight of briquette before immersion while $W_{\mathrm{ii}}$ is weight of briquette after immersion.

\section{Results and Discussion}

\subsection{Briquettes produced with rice husk and sugarcane bagasse}

The briquettes produced from the combination of rice husk $(\mathrm{RH})$ and sugarcane bagasse were illustrated in Figure 6 according the mixing ratio.

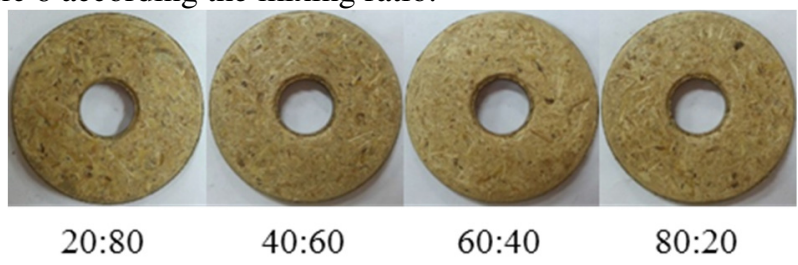

Fig. 6. Briquettes Of RH: SB (wt. \%).

Fig. 7depicted the trend plot of mechanical properties of the briquettes formed with different mixing ratio rice husk $(\mathrm{RH})$ and sugarcane bagasse (SB). The results reflecting the strength and durability of the pure RH and SB briquettes were also plotted in the graphs, acting as the controls or reference. It was observed that the briquettes made from SB were shown to have higher strength and durability as compared to that of RH, except the water resistance. Therefore, mixing between these two biomass residues was anticipated to produce the briquettes with better strength and durability. 


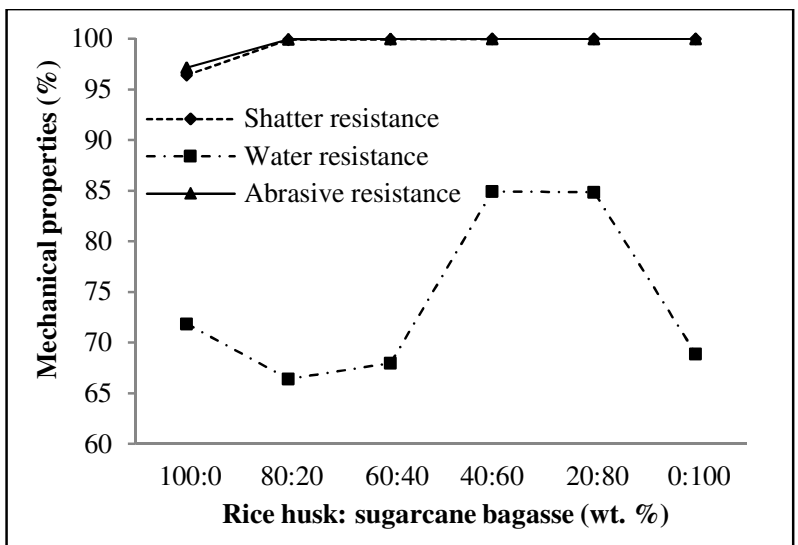

Fig. 7. Effect of mixing ratio to the mechanical properties of the briquettes with the blends of RH and SB.

As illustrated in Figure 7, the shatter resistance and abrasive resistance of the briquettes with different blends ratio portrayed a similar trend. As reviewed by Kaliyan and Valence Morey [8] as a reference, a quality briquette should fulfil the specifications by having $\geq 90 \%$ and $\geq 95 \%$ in shatter resistance and abrasive resistance respectively. By taking this reference, the briquettes formed in different mixing ratio were having shatter resistance and abrasive resistance from around $96 \%$ to $100 \%$, falling within the range of acceptance limit and thus they were considered as quality briquettes. On top of that, the effect of mixing ratio on the foregoing mechanical properties was insignificant.

On the other hand, there was significant effect of different mixing ratio for $\mathrm{RH}$ and SB briquettes on their water resistance property as displayed in Figure 7. The maximum water resistance $(84.97 \%$ ) was recorded in the briquettes formed in 40:60 of RH to SB, with 13.11 $\%$ to $16.06 \%$ of increment as compared to the pure residues briquettes. Surprisingly, the briquettes produced from higher SB compositions exhibited lower water absorption property although the water resistance of pure SB briquettes was $2.95 \%$ lower than that of RH. This was an indication for the success of blending between RH and SB as the water resistance could be improved significantly. However, these briquettes did not fall within the range of acceptance limit for water resistance, $\geq 95 \%$ [8].

By summarising the mechanical properties from the results obtained and discussed, the briquettes formed with 20:80 could be considered as the optimum mixing ratio for the blends of RH and SB. The strength and durability of these mixing ratio was the best among the four mixing ratio. With regard to the water resistance, it is fine if the briquettes were not applied under high humid environment such as fish pellet, requiring higher water resistance property.

\subsection{Briquettes with rice husk and spent coffee ground}

Figure 8 presented the image of the briquettes produced from the mixture of rice husk $(\mathrm{RH})$ and spent coffee ground (SCG) with four different mixing ratio.

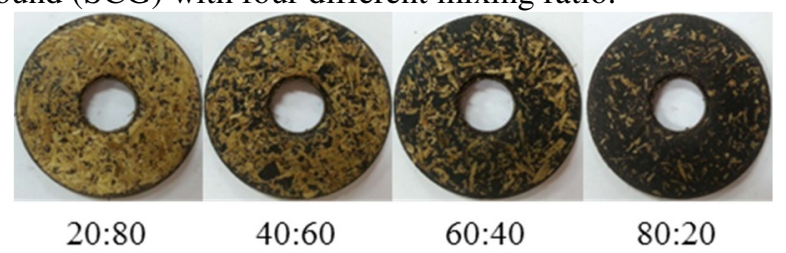

Fig. 8. Briquettes of RH: SCG (wt. \%). 
The mechanical strength and durability of the briquettes with the blends of RH and SCG in different mixing ratio were portrayed in Figure 9.

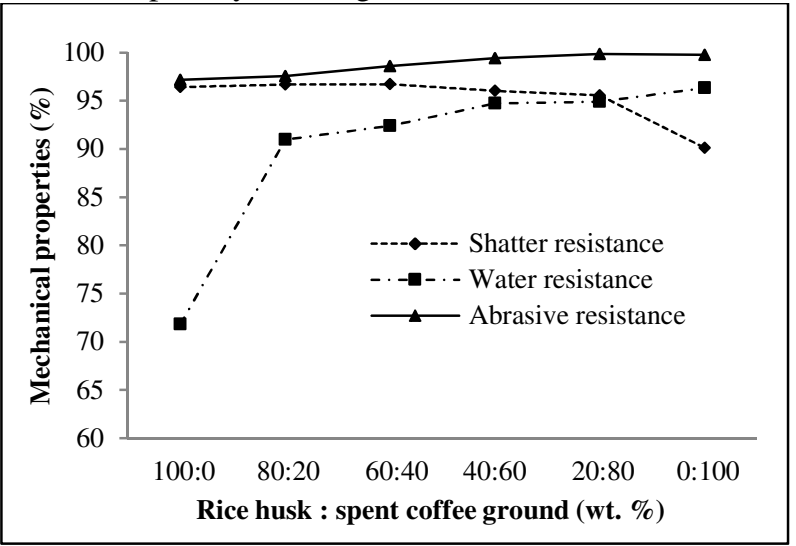

Fig. 9. Effect of mixing ratio to the mechanical properties of the briquettes with the blends of RH and SCG.

With respect to the shatter resistance of the briqeuttes, the value ranged $90.14 \%$ to 96.77 $\%$ whereby the pure SCG briquettes exhibited the lowest shatter resistance, and 60: 40 of RH to SCG briquettes were having highest shatter resistance. On top of that, the hardness of the pure SCG briquettes was lower as compared to that of pure RH as shown in Figure 9. Unlike the previous combination discussed in section 3.1, the incorporation of SCG in the RH briqeuttes did not improve the hardness of the briquettes as what SB did. In another point of view, however, the hardness briqeuttes formed with the blends of RH and SCG had been improved by at least $5.44 \%$ as compared to that of pure SCG briquettes. Moreover, these blends briqueuttes had fufilled the accepatnce limit by having $\geq 90 \%$ in shatter resistance.

From Figure 9, it could be seen that the water resistance and abrasive resistance of the briquettes increased with the increased of SCG weight ratio. The increment on the abrasive resistance could be claimed as insignificant in which the deviation was about $2.68 \%$ between highest and lowest values. Of course, the briquettes formed with RH and SCG were obtaining abrasive resistance $\geq 95 \%$, which was within the range of acceptance limit. In the case of water resistance, a significant increment could be seen in this particular property when SCG compositions were higher. From Figure 9, the results demonstrated that the pure SCG briquettes exceeded pure RH briquettes with respect to the water resistance with $24.51 \%$ of deviation. From the results shown, mixing of SCG with RH were anticipated to produce a briquette with better water resistance characteristics due to its hydrophobic characteristics. Besides that, the oil content within the SCG could act as the protective layer to prevent the particles dissolved in water and disintegrated.

In overview, blending of RH and SCG was acceptable for the mechanical properties of the briquettes had been improved and these materials were able to complement each other to form a quality briquette by fulfilling the specification required. The optimum mixing ratio for RH to SCG would be 20: 80 where an intersection point existed between shatter resistance and water resistance, at the same time, the abrasive resistance was among the highest at that point.

\subsection{Briquettes with sugarcane bagasse and spent coffee ground}

Sugarcane bagasse (SB) and spent coffee ground (SCG) were blended in different mixing ratio to form the briquettes as shown in Figure 10. 


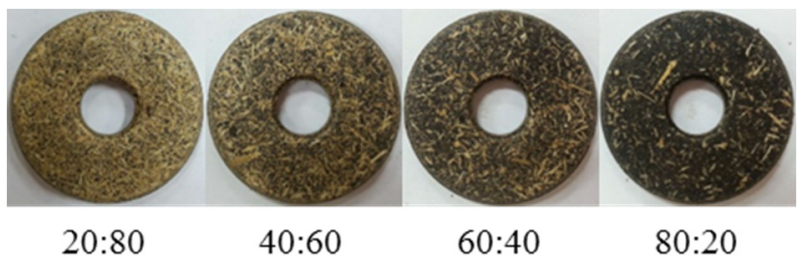

Fig. 10. Briquettes formed with sugarcane bagasse and spent coffee ground

For the combination of sugarcane bagasse (SB) spent coffee ground (SCG), the effect of mixing ratio to the mechanical strength and durability could be viewed from Figure 11.

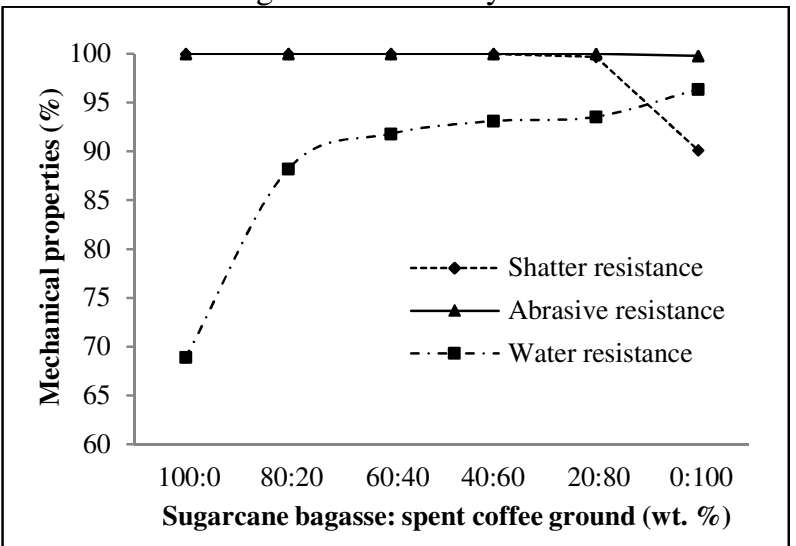

Fig. 11. Effect of mixing ratio to the mechanical properties of the briquettes with the blends of SB and SCG.

The experimental results presented a positive outcome of the mixing of SB and SCG, indicating a better quality of briquettes. Briquettes formed with pure SB had been experimentally proven to have $100 \%$ in shatter resistance and abrasive resistance, indicating that there were no fines produced when encountering the destructive forces. The briquettes remained intact after the drop test and tumbling test. This could be attributed to its fibrous structure, softer surface and lignin content. SB contained about $22 \%$ of lignin [23] which played an important role in binding. When temperature was applied during densification, the plant lignin was softened and activated, thus promoting to a better binding process. In SB briquettes, the mechanical interlocking resulted from the compaction of fibrous, flat-shaped particles [24] existed and provided rigidity to the briquettes' structure. On the contrary, the abrasive resistance and shatter resistance of SCG briquettes were slightly lower by $0.21 \%$ and $9.86 \%$ as compared to that of SB due to its lower lignin $(0.05 \%)$ and fibre $(0 \%)$ contents [25]. Mixing of SB and SCG was shown to raise the quality of the briquettes. From Fig. 8, there were no changes in the abrasive resistance of the briquettes produced from SCG with SB for the entire mixing ratio. Only $0.03-0.32 \%$ of decrement was resulted in the shatter resistance of these briquettes especially when higher SCG compositions were incorporated. According to the acceptance limit for the foregoing mechanical properties, the briquettes with 4 different mixing ratios has fall within the range of specifications.

In the case of water resistance, pure SB briquettes exhibited the highest water absorption characteristics due to its hydrophobic characteristics. SB was claimed to have a high absorption properties and thus used for many application as its cellulose fibres were pretreated and used as reinforcing filler in high density polyethylene composites [26]. Also, the comminuted sugarcane bagasse was fine enough and softer, which could lead to water absorption. SCG briquettes, on the other hand showed the least water absorption property due to the oil content. The outer SCG particles might contain oil and form a layer which 
would inhibit or slow down water penetration. As observed from Fig. 8, it was found that the water resistance of the briquettes has increased $19.3 \%$ when $20 \mathrm{wt}$. \% of SCG added to the SB briquettes, and continuously increased when 40 wt. $\%, 60$ wt. $\%$ and 80 wt. $\%$ of SCG were incorporated. In addition, $93.12 \%$ and $93.55 \%$ were achieved from 40: 60 and 20:80 of SB to SCG briquettes, which were nearly fulfil the acceptance limit of water resistance ( $\geq$ $95 \%)$.

According to the results and analysis done, there was an intersection point at the mixing ratio of 10: 90, showing the mechanical properties of these blends briquettes were optimised. However, in order to balance up the usage of these two residues, 20: 80 of SB to SCG was decided as the optimum mixing ratio in this study. From Figure 11, the mechanical properties of the briquettes were among the highest as compared to other mixing ratio and meeting the standards by referring to the standard limit.

\section{Conclusion}

In conclusion, the objective of this study has been achieved whereby the mechanical properties of the briquettes formed with different biomass combinations were studied and lastly the optimum mixing ratio for each combination was selected. For the combination of RH to SB, the optimised mixing ratio was 40:60, whereas 20:80 was chosen for RH to SCG and SB to SCG respectively. The briquettes produced from different combination at these optimised mixing ratio were shown to have higher mechanical strength and durability in terms of shatter resistance, abrasive resistance as well as water resistance. The residues exhibited different nature characteristics and thus it was anticipated to complement each other after mixing to improve the strength and durability of the final densified product. On top of that, this particular method could be applied in the industrial as one of the alternatives to make good use of the natural resources and not only focusing on single materials.

\section{References}

1. J. Wang, L. Feng, X. Tang, Y. Bentley, and M. Höök, Futures 86, pp. 58-72 (2017).

2. H. Garrett-Peltier, Econ. Model. 61, pp. 439-447 (2017).

3. A. Demirbas, Energy Sources, Part A Recover. Util. Environ. Eff. 31(19), pp. 16941699 (2009).

4. N. Asim, Z. Emdadi, M. Mohammad, M. A. Yarmo, and K. Sopian, J. Clean. Prod. 91, pp. 26-35 (2015).

5. B. Missagia, C. Guerrero, S. Narra, Y. Sun, P. Ay, and H. J. Krautz, Energy \& Fuels 25(12), pp. 5786-5790 (2011).

6. P. Basu, Biomass Gasification and Pyrolysis : Practical Design and Theory (Academic Press, 2010).

7. W.-H. Chen, J. Peng, and X. T. Bi, Renew. Sustain. Energy Rev. 44, pp. 847-866 (2015).

8. N. Kaliyan and R. Vance Morey, Biomass and Bioenergy 33(3), pp. 337-359 (2009).

9. R. I. Muazu and J. A. Stegemann, Fuel Process. Technol. 133, pp. 137-145 (2015).

10. S. A. Rahaman and P. A. Salam, Fuel Process. Technol. 158, pp. 9-19 (2017).

11. P. D. Lund, J. Byrne, G. Berndes, and I. A. Vasalos, Advances in Bioenergy: The Sustainability Challenge (John Wiley \& Sons, 2016).

12. Z. Liu and G. Han, Fuel 158, pp. 159-165 (2015).

13. S. Pandey and R. P. Dhakal, Int. J. Energy Sci. 3(3), (2013).

14. V. Strezov and T. J. Evans, Biomass Processing Technologies, 1st ed. (CRC Press, 2014).

15. L. Chen, L. Xing, and L. Han, Renew. Sustain. Energy Rev. 13(9), pp. 2689-2695 
(2009).

16. P. K. Adapa, L. G. Tabil, and G. J. Schoenau, Compression Characteristics of Selected Ground Agricultural Biomass 11, (International Commission of Agricultural Engineering, 2009).

17. T. Wongsiriamnuay and N. Tippayawong, Biosyst. Eng. 139, pp. 111-120 (2015).

18. S. A. Ndindeng, J. E. G. Mbassi, W. F. Mbacham, J. Manful, S. Graham-Acquaah, J. Moreira, J. Dossou, and K. Futakuchi, Energy Sustain. Dev. 29, pp. 24-31 (2015).

19. S. H. Sengar, A. G. Mohod, Y. P. Khandetod, S. S. Patil, and A. D. Chendake, Int. J. Energy Eng. 2(1), pp. 28-34 (2012).

20. V. R. Birwatkar, Y. P. Khandetod, A. G. Mohod, and K. G. Dhande, Ind. J. Sci. Res. Tech. 2(4), pp. 55-62 (2014).

21. E. Repsa, E. Kronbergs, and E. Pudans, Eng. Rural Dev. 29-30, pp. 436-439 (2014).

22. R. M. Davies and O. A. Davies, J. Combust. 2013, pp. 1-7 (2013).

23. C. Rezende, M. de Lima, P. Maziero, E. deAzevedo, W. Garcia, and I. Polikarpov, Biotechnol. Biofuels 4(1), pp. 54 (2011).

24. J. S. Tumuluru, C. T. Wright, J. R. Hess, and K. L. Kenney, Biofuels, Bioprod. Biorefining 5(6), pp. 683-707 (2011).

25. P. S. Murthy and M. Madhava Naidu, Resour. Conserv. Recycl. 66, pp. 45-58 (2012).

26. D. R. Mulinari, H. J. C. Voorwald, M. O. H. Cioffi, G. J. M. Rocha, and M. L. C. P. Da Silva, BioResources 5(2), pp. 661-671 (2010). 